\title{
New Polymer Syntheses Part 59. Synthesis and Characterization of New Polyamides and Copolyamides Containing Thianthrene Moiety and Based on Methyl- and/or Tertiarybutyl-Cyclohexanone in the Main Chain
}

\author{
Kamal I. Aly, and Dirk Kuckling ${ }^{2}$ \\ ${ }^{1}$ Polymer Research Laboratory, Chemistry Department, Faculty of Science, Assiut University, Assiut 71516, \\ Egypt \\ ${ }^{2}$ Department Chemie, Universität Paderborn, Warburger Str. 100, D-33098 Paderborn, Germany
}

\begin{abstract}
Two new series of polyamides and copolyamides based on methyl-cyclohexanone and tertiary-butylcyclohexanone in the main chain were synthesized via the solution polymerization of 2,6-bis(m-aminobenzylidene)methylcyclohex-anone VI, 2,6-bis(m-aminobenzylidene)tertiary-butyl-cyclohexanone VIII, and its copolyamides with $p$ phenylene diamines and $m$-phenylene diamines with diacid chlorides of thianthrene (2,7-Dichloroformylthianthrene$5,5^{\circ}, 10,10^{\circ}$-tetraoxide IV. These polyamides and copolymides ranged from yellow to orange color and had inherent viscosity up to $0.35-0.89 \mathrm{dL} / \mathrm{g}$. All the polyamides and copolymides were insoluble in common organic solvents but dissolved completely in concentrated $\mathrm{H}_{2} \mathrm{SO}_{4}$. The thermal stabilities of the prepared polyamides were evaluated by TGA and DTG analyses. X- ray analysis showed these polymers having low degree of crystallinity in the region $2 \theta=5-60^{\circ}$. The morphological properties of some selected polyamides were detected by SEM.
\end{abstract}

Keywords: Polyamides, Copolyamides, Thianthrene, Thermal Properties, arylidene polymers.

\section{INTRODUCTION}

Aramids have been known for their high heat resistance and high strength. The alkyl:aryl polyamides are derived from aliphatic primary and secondary diamines, cycloaliphatic secondary diamines, and $\mathrm{N}$ substituted aliphatic-aromatic series. In addition to having extremely high polymer melt temperatures, they are soluble in strong acids such as sulfuric acid and trifluoroacetic acid. Wholly aromatic polyamides possess high thermal stability [1]; however, their non treatment is limits their applications [2]. Thus, the properties of aramids were determined by high concentration due to strong polar bonds and its rigidity of $p$-phenylene unit. Structural modification such as the introduction of (1) a bulky pendant substituent [3-5], (2) the nature of the parent chain (e.g. types of linkages and aromatic units) [6-8], (3) non-coplanar biphenylene moieties [9], and (4) flexible alkyl spacers [10] have been reported to enhance the solubility and to lower the phase transition temperatures. Copolymers having sulfone, imide, ether, and sulfide linkages lead to flexibility without compromising thermal stability [8, 10, 11, 12-18]. In general, methyl groups present in these polymers tend to lower the glass transition temperatures, lower thermal stability, and increased air

*Address correspondence to this author at the Polymer Research Laboratory, Chemistry Department, Faculty of Science, Assiut University, Assiut 71516, Egypt; Tel: 0020 882412114; Fax: 0020 882367100;

E-mail: kamalaly@yahoo.com, kamalaly@aun.edu.eg oxidation. Modifications such as introduction of flexible or nonsymmetrical thermally stable linkages in the backbone or introduction of large polar, nonpolar, or non-coplanar substituents along the polymer backbone disrupt the symmetry by copolymerization of two different diamines/diacid structures. Up to this date, no report has appeared on the synthesis of linear unsaturated polyamides with thianthrene units in the polymer backbone. The work presented here outlines the synthesis and characterization of new polyamides and copolymaides of diarylidenecycloalkanones that include thianthrene moieties. A major target for this work was to study the effect of alkyl-cycloalkanone moeity on the thermal stability properties of the polyamides. The crystallinity, solubility, and morphologic properties of this new class of polyamides were also examined.

\section{EXPERIMENTAL}

\subsection{Measurements}

Elemental analyses were carried out using an Elemental Analyses system $\mathrm{GmbH}$, VARIOEL, $\mathrm{V}_{2.3}$ July 1998 CHNS Mode. FT-IR spectra were recorded on IR470, Infrared spectrophotometer, Shimadzu by using the $\mathrm{KBr}$ pellet technique. The ${ }^{1} \mathrm{H}-\mathrm{NMR}$ spectra were recorded on a GNM-LA 400-MHz NMR spectrophotometer at room temperature in DMSO or $\mathrm{CDCl}_{3}$ using TMS as the internal reference. Inherent viscosities of polymer solutions $(0.5 \% \mathrm{w} / \mathrm{v})$ in $\mathrm{H}_{2} \mathrm{SO}_{4}$ 
were determined at $30{ }^{\circ} \mathrm{C}$ using an Ubbelohde suspended level viscometer. The solubility of polymers was examined using $0.02 \mathrm{~g}$ of polymer in $3-5 \mathrm{ml}$ of solvent at room temperature. The electrical conductivities were measured using a Keithly electrometer (610C). The X-ray diffractographs of the polymers were obtained with a Philips X-ray PW1710 diffractometer, and $\mathrm{Ni}$ - filtered CuK $\alpha$ radiations Thermogravimetric analysis (TGA) and differential thermal gravimetric (DTG) were carried out in air with Shimadzu DTG-60 at heating rate of $10^{\circ} \mathrm{C} / \mathrm{min}$. in air. The morphology of a selected example of polyamide XVIII was examined by SEM (Jeol JSM-5400 LV instrument). The SEM sample was prepared by evaporating a dilute solution of polymer on a smooth surface of aluminium foil, and subsequently coating it with gold palladium alloy. SEM images were taken on a Pentaz Z-50 P Camera with Ilford film at an accelerating voltage of $15 \mathrm{KV}$ using a low dose technique.

\subsection{Reagents and Solvents}

Methyl-cyclohexanone (Merck, 99\%), tert.butylcyclohexanone (Merck, 99\%) and anhydrous lithium chloride (Merck) were used without purification. Benzoyl chloride and thionyl chloride (Aldrich, 98\%) were used without purification. Carbon disulphide: distillation of appreciable quantities of $\mathrm{CS}_{2}$ should be carried out in a water bath at $55-65^{\circ} \mathrm{C}$. $p$ Phenylendiamines (m.p. $138-143{ }^{\circ} \mathrm{C}$ ) and $m$ phenylendiamines (m.p. $64-66{ }^{\circ} \mathrm{C}$ ), (Aldrich, 98\%) were used as recived. Anhydrous $\mathrm{AlCl}_{3}$ (Merck) was used as it is. $m$-Nitrobenzaldehyde (Sigma, m.p. $55-58{ }^{\circ} \mathrm{C}$ ) used as it is. All other reagents were of high purity and were further purified as reported in literature [19].

\subsection{Monomer Synthesis}

\subsubsection{Thianthrene (I)}

Thianthrene was prepared as described in the literature [20].

\subsubsection{2,7-Diacetylthianthrene (II)}

A solution of thianthrene I $(8.89 \mathrm{~g}, 0.04 \mathrm{~mol})$ in $50 \mathrm{ml}$ of dry $\mathrm{CS}_{2}$ was added dropwise to a stirred mixture of acetyl chloride $(25.76 \mathrm{~g}, 0.326 \mathrm{~mol})$ and anhydrous $\mathrm{AlCl}_{3}(22.4 \mathrm{~g}, 0.364 \mathrm{~mol})$ in $150 \mathrm{ml} \mathrm{CS}$. During the addition, the temperature of the reaction was kept at $10^{\circ} \mathrm{C}$. After the end of the addition, the reaction mixture was stirred at ambient temperature for $20 \mathrm{~h}$ and then poured onto crushed ice/ $\mathrm{HCl}$. The solid product formed was filtered off, washed with water, dried, and then recrystallized from an ethanol-benzene mixture $(4: 1)$ as pale yellow needles to afford the desired product as a pale yellow needle. Yield $70 \%$, mp $175^{\circ} \mathrm{C}$, literature [21] $175^{\circ} \mathrm{C} . \quad \mathrm{IR} \quad(\mathrm{KBr}) 1695 \mathrm{~cm}^{-1} \quad(\mathrm{C}=\mathrm{O}) ;{ }^{1} \mathrm{H}-\mathrm{NMR}$ $\left(\delta / \mathrm{CDCl}_{3}\right)$ showed at $7.35-8.15(\mathrm{~m}, 6 \mathrm{H}$ of $\mathrm{Ar}-\mathrm{H})$ and at $2.65\left(\mathrm{~s}, 6 \mathrm{H}\right.$ of $\left.2 \mathrm{COCH}_{3}\right) \mathrm{ppm}$.

\subsubsection{Synthesis of 2,7-thianthrenedicarboxylic acid-5, $5^{\prime}, 10,10^{\prime}$-tetraoxide (III)}

Compound (III) was prepared in $89 \%$ yield by oxidation of II by using a procedure similar to that given in ref [21] $\mathrm{mp}>300$. Analysis Calculated for $\mathrm{C}_{14} \mathrm{H}_{8} \mathrm{O}_{8} \mathrm{~S}_{2}$ : C45.69; H2.77; S,17.46. Found: C45.53; $\mathrm{H}, 2.09$; S, 17.59. IR (KBr) $1715 \mathrm{~cm}^{-1}(\mathrm{C}=\mathrm{O}), 3350-3100 \mathrm{~cm}^{-1}(\mathrm{OH})$, $1310,1165,1130 \mathrm{~cm}^{-1}\left(\mathrm{SO}_{2}\right) .{ }^{1} \mathrm{H}-\mathrm{NMR}$ (ס/DMSO- $\left.d_{6}\right)$ showed at 7.5-8.45 (m, $6 \mathrm{H}$ of $\mathrm{Ar}-\mathrm{H})$ and at $5.8(\mathrm{~s}, 2 \mathrm{H}$ of $\mathrm{COOH}) \mathrm{ppm}$.

\subsubsection{Synthesis of 2,7- dichloroformylthianthrene - $5,5^{\circ}, 10,10^{\circ}$-tetraoxide(IV)}

A mixture of diacid III $(7.2 \mathrm{~g}, 0.02 \mathrm{~mol})$ was boiled in $50 \mathrm{ml}$, of thionyl chloride in the presence of few drops of pyridene as catalyst. The excess of thionyl chloride was distilled off and the residual matter was recrystallized from benzene- petroleum ether 60-80 (1:1), yield $85 \%, \mathrm{mp} 180{ }^{\circ} \mathrm{C}$. Analysis Calculated for $\mathrm{C}_{14} \mathrm{H}_{6} \mathrm{O}_{6} \mathrm{~S}_{2} \mathrm{Cl}_{2}: \mathrm{C}, 41.58 ; \mathrm{H} 1.48 ; \mathrm{S}, 15.84, \mathrm{Cl}, 17.32$. Found: C, 41.50; $\mathrm{H}, 1.50 ; \mathrm{S}, 15.70 ; \mathrm{Cl}, 17.21 . \mathrm{IR}(\mathrm{KBr})$ $1765 \mathrm{~cm}^{-1}(\mathrm{C}=\mathrm{O}), 1320,1180,1120 \mathrm{~cm}^{-1}\left(-\mathrm{SO}_{2}\right)$.

\subsubsection{2,5-Bis(m-nitrobenzylidene) methyl-cyclohex- anone (V)}

A mixture of the $m$-nitrobenzaldehyde $(30.21 \mathrm{~g}, 0.2$ mole), methyl-cyclohexanone (10.70 g, 0.1 mole), and ethanol $(95 \%, 100 \mathrm{ml})$ was introduced in a conical flask $(250 \mathrm{ml})$. The mixture was warmed at about $50{ }^{\circ} \mathrm{C}$ to obtain a solution, and few drops of catalytic $\mathrm{KOH}(20 \%)$ were added with stirring for 2 hrs. An exothermic reaction was observed, while a highly yellowish solid separated out. It was filtered off, washed thoroughly with water and recrystallized as yellow needles from ethanol; yield: $97 \%$. Anal. Calcd. for $\mathrm{C}_{21} \mathrm{H}_{14} \mathrm{~N}_{2} \mathrm{O}_{5}$ : Calcd. \%: C,67.38; H,3.74; N,7.49. Found \%:C,67.03; $\mathrm{H}, 3.20 ; \mathrm{N}, 7.07$.

\subsubsection{2,6-Bis(m-aminobenzylidene)methyl-cyclohe- xanone (VI)}

A flask was charged with a mixture of compound $\mathbf{V}$ $(3.067 \mathrm{~g}, 8.52 \mathrm{mmol})$, ethanol $(95 \% 40 \mathrm{ml})$, and a catalytic quantity of $10 \%$ palladium on activated carbon. Hydrazine hydrate $(4 \mathrm{ml})$ diluted with ethanol $(10 \mathrm{ml})$ was added dropwise to the stirred mixture at $60^{\circ} \mathrm{C}$. It was subsequently heated at this temperature 
for $30 \mathrm{~min}$. The solid gradually dissolved during hydrogenation. The reaction mixture was filtered off and the filtrate was concentrated by rotary evaporation. The residue was dried in a vacuum oven to yield a compact pale yellow solid. An analytical sample was obtained by recrystallization from ether/THF (1:1) in the form of yellowish crystals $(90 \%$ yield). Anal. Calc. for $\mathrm{C}_{21} \mathrm{H}_{18} \mathrm{~N}_{2} \mathrm{O}: \mathrm{C}, 80.25 ; \mathrm{H}, 5.73 ; \mathrm{N}, 8.92$. Found: $\mathrm{C}$, 79.27; H, 5.18; N, 8.27. IR $\left(\mathrm{KBr}, \mathrm{cm}^{-1}\right): 3460-3190(\mathrm{NH}$ stretching); 2950-2870 (cyclohexanone $\mathrm{C}-\mathrm{H}$ stretching); 1660 ( $\mathrm{C}=\mathrm{O}$ of cyclohexanone); $1600(\mathrm{C}=\mathrm{C}) ; 695(\mathrm{NH}$ deformation). ${ }^{1} \mathrm{H}-\mathrm{NMR}$ (DMSO- $\left.d_{6} \mathrm{ppm}\right)$ : 6.39-7.04 (m, $8 \mathrm{H}$ of $\mathrm{Ar}-\mathrm{H}$ and $2 \mathrm{H}$ of $2 \mathrm{CH}=\mathrm{C}$ ); $4.98\left(\mathrm{~s}, 4 \mathrm{H}\right.$ of $2 \mathrm{NH}_{2}$ ); $3.10,3.45(\mathrm{~m}, 4 \mathrm{H}$ of cyclohexanone $) ; 1.23-1.35(\mathrm{~m}, 3 \mathrm{H}$ of methyl group).

\subsubsection{2,6-Bis(m-nitrobenzylidene) tert.butylcyclohe- xanone (VII)}

A mixture of the $m$-nitrobenzaldehyde $(30.21 \mathrm{~g}, 0.2$ mole), tert.butyl-cyclohexanone (14.90 g, $0.1 \mathrm{~mole})$, and ethanol $(95 \%, 100 \mathrm{ml})$ was introduced in a conical flask $(250 \mathrm{ml})$. The mixture was warmed at about $50^{\circ} \mathrm{C}$ to obtain a solution, and few drops of catalytic $\mathrm{KOH}$ $(20 \%)$ were added with stirring for $2 \mathrm{hrs}$. An exothermic reaction was observed, while a highly yellowish solid separated out. It was filtered off, washed thoroughly with water and recrystallized from as yellow crystals from ethanol; yield: $93 \%$. Anal. Calcd. for $\mathrm{C}_{24} \mathrm{H}_{20} \mathrm{~N}_{2} \mathrm{O}_{5}$ : Calcd. \%: C, 69.23; H, 4.81; N, 6.73. Found \%:C, $67.31 ; \mathrm{H}, 4.23 ; \mathrm{N}, 6.27$.

\subsubsection{2,6-Bis(m-aminobenzylidene) ter.butyl-cyclo- hexanone (VIII)}

A procedure similar to that used for VII was followed. An analytical sample of VIII ( $85 \%$ yield) was obtained as yellowish crystals recrystallization from ether/THF. Anal. Calc, for $\mathrm{C}_{24} \mathrm{H}_{24} \mathrm{~N}_{2} \mathrm{O}: \mathrm{C}, 80.90 ; \mathrm{H}$, $6.74 ; \mathrm{N}, 7.87$. Found: $\mathrm{C}, 80.15 ; \mathrm{H}, 6.221$; N, 7.32. IR $\left(\mathrm{KBr}, \mathrm{cm}^{-1}\right): 3350$ (NH stretching); 2900 (C-H of acetone); 1695 ( $\mathrm{C}=\mathrm{O}$ of cyclohexanone); $1585(\mathrm{C}=\mathrm{C})$; 685 (NH deformation). ${ }^{1} \mathrm{H}-\mathrm{NMR}$ (DMSO- $\mathrm{d}_{6} \mathrm{ppm}$ ): 6.4$7.4(\mathrm{~m}, 8 \mathrm{H}$ of $\mathrm{Ar}-\mathrm{H}$ and $4 \mathrm{H}$ of $2 \mathrm{CH}=\mathrm{CH}) ; 4.0-4.5(4 \mathrm{H}$ of $\left.2 \mathrm{NH}_{2}\right), 1.23-1.35$ (m, $9 \mathrm{H}$ of ter. butyl group).

\subsection{Synthesis of Model Compounds}

\subsubsection{2,6-Bis(m-aminobenzylidene)methyl-cyclohe- xanone dibenzamide (IX)}

Triethylamine $(8.0 \mathrm{mmol})$ was added to a solution of 2,5-Bis (m-aminbenzylidene)cyclopentanone IX (4 $\mathrm{mmol})$ in DMF $(15 \mathrm{ml})$. Benzoyl chloride $(8.0 \mathrm{mmol})$ diluted with DMF $(8 \mathrm{ml})$ was added to the stirred solution under $\mathrm{N}_{2}$ at $0^{\circ} \mathrm{C}$. The mixture was subsequently stirred at room temperature in a stream of $\mathrm{N}_{2}$ for $2 \mathrm{hr}$. The solid product was filtered off, washed with dilute aq. $\mathrm{NaHCO}_{3}$, then with water and dried to afford XIII. An analytical sample was obtained by recrystallization from Ethanol/Ether (84\% yield). Anal. Calc, for $\mathrm{C}_{35} \mathrm{H}_{25} \mathrm{~N}_{2} \mathrm{O}_{3}$ : C, 80.61; $\mathrm{H}, 4.80 ; \mathrm{N}, 5.37$. Found: C, 80.02; $\mathrm{H}, 5.12 ; \mathrm{N}, 5.06$. IR $\left(\mathrm{KBr}, \mathrm{cm}^{-1}\right)$ : 33003200 (NH stretching); 3020 (cyclopentanone $\mathrm{C}-\mathrm{H}$ stretching); 1690-1620 (amid $\mathrm{C}=\mathrm{O}$, cyclopentanone $\mathrm{C}=\mathrm{O}$ and $\mathrm{C}=\mathrm{C}) ; 680 \quad(\mathrm{NH}$ deformation); 1435 (cylohexanone $\mathrm{C}-\mathrm{H}$ deformation); 1310 (C-H stretching of the olefinic bond). ${ }^{1} \mathrm{H}-\mathrm{NMR}$ (DMSO- $d_{6} \mathrm{ppm}$ ): 10.5 ( $2 \mathrm{H}$ of $2 \mathrm{NHCO}) ; 8.1$ (8H, aromatic ortho to $\mathrm{C}=0$ ); 7.1 $7.7(\mathrm{~m}, 10 \mathrm{H}$ other aromatic and $2 \mathrm{H}$ olefinic); $3.2-3.5(\mathrm{~m}$, $4 \mathrm{H}$ of cyclohexanone); $1.25-1.45(\mathrm{~m}, 3 \mathrm{H}$ of methyl group).

\subsubsection{2,6-Bis(m-aminobenzylidene) tert.butyl-cyclo- hexanone dibenzamide $(X)$}

Using a procedure similar to that described for compounds IX, analytical sample of compound X ( $89 \%$ yield) was obtained in the form of pale yellow crystalls after recrystallziation from ethanol/ether (2:1). Anal. Calc. for $\mathrm{C}_{38} \mathrm{H}_{31} \mathrm{~N}_{2} \mathrm{O}_{3}$ : C,80.99; $\mathrm{H}, 4.97 ; \mathrm{N}, 5.93$. Found $\mathrm{C}, 80.10 ; \mathrm{H}, 4.35 ; \mathrm{N}, 5.16$. IR $\left(\mathrm{KBr}, \mathrm{cm}^{-1}\right) 3300-3200$ ( $\mathrm{NH}$ stretching); 3020 (acetone $\mathrm{C}-\mathrm{H}$ stretching); 16901620 (amide $\mathrm{C}=\mathrm{O}, \mathrm{C}=\mathrm{O}$ and $\mathrm{C}=\mathrm{C}$ ); $670 \quad(\mathrm{NH}$ deformation); 1420 (C-H deformation);1305 (C-H stretching of the olefinic bond). ${ }^{1} \mathrm{H}-\mathrm{NMR}$ (DMSO- $d_{6}$ ppm): 10.5 (2H of $2 \mathrm{NHCO}) ; 8.0(\mathrm{~m}, 4 \mathrm{H}$, aromatic ortho to $\mathrm{C}=\mathrm{O}$ and $2 \mathrm{CH}=\mathrm{C}$ olefinic); 7.1-7.7 $(\mathrm{m}, 14 \mathrm{H}$ other aromatic and $2 \mathrm{H}$ olefinic); $1.13-1.38$ (m, $9 \mathrm{H}$ of ter. butyl group).

\subsection{Synthesis of Polyamides XI and XII}

These polymers were prepared according to the following general procedure, as described here for the polyamide XI. To a flask charged with a mixture 2,6bis( $m$-nitrobenzylidene) methyl-cyclohexanone $\mathbf{V}$ $(1.740 \mathrm{~g}, \quad 6.0 \mathrm{mmol})$, DMF or NMP $(15 \mathrm{ml})$, triethylamine $(1.214 \mathrm{~g}, 12 \mathrm{mmol})$ and a solution of 2,7 Dichloroformylthianth-rene $-5,5^{\circ}, 10,10^{\circ}$-tetraoxide (IV) $(1.215 \mathrm{~g}, 6.0 \mathrm{mmol})$ in DMF $(15 \mathrm{ml})$ was added dropwise and mainting the stirred solution at $0^{\circ} \mathrm{C}$ under $\mathrm{N}_{2}$. The mixture was subsequently stirred at ambient temperature in a stream of $\mathrm{N}_{2}$ for $3 \mathrm{hr}$, then it was poured into ice-water to give a yellowish to deep yellow colored solid. This was filtered off, washed with dilute aqu. $\mathrm{NaHCO}_{3}$, then with water, ethanol, acetone and finally dried under reduced pressure $(1 \mathrm{mmHg})$ at $70^{\circ} \mathrm{C}$ for 2 days, The synthesized polyamides XI-XII their physical properties are listed in Table $\mathbf{1}$. 
Table 1: Elemental Analyses, Inherent Viscosity and Yield of Polyamides XI, XII and Copolyamides XIII-XVII

\begin{tabular}{|c|c|c|c|c|c|c|c|c|c|c|c|}
\hline \multirow{2}{*}{$\begin{array}{c}\text { Polymer } \\
\text { Code }\end{array}$} & \multirow{2}{*}{$\begin{array}{c}\text { Repeating } \\
\text { unit }\end{array}$} & \multicolumn{2}{|c|}{ C\% } & \multicolumn{2}{|c|}{$\mathrm{H} \%$} & \multicolumn{2}{|c|}{ N\% } & \multicolumn{2}{|c|}{ S\% } & \multirow{2}{*}{$\begin{array}{c}\eta_{\operatorname{lnh}} \\
(\mathrm{dl} / \mathrm{g})\end{array}$} & \multirow{2}{*}{$\begin{array}{r}\text { Yield } \\
(\%)\end{array}$} \\
\hline & & Calcd. & Found & Calcd. & Found & Calcd. & Found & Calcd. & Found & & \\
\hline XII & $\begin{array}{c}\mathrm{C}_{37} \mathrm{H}_{31} \mathrm{O}_{7} \mathrm{~N}_{2} \mathrm{~S}_{2} \\
(679)\end{array}$ & 65.39 & 64.16 & 4.57 & 4.09 & 4.12 & 3.23 & 9.43 & 9.03 & 0.89 & 73 \\
\hline XIV & $\begin{array}{c}\mathrm{C}_{42} \mathrm{H}_{31} \mathrm{O}_{8} \mathrm{~N}_{4} \mathrm{~S}_{2} \\
(783)\end{array}$ & 64.37 & 63.51 & 3.96 & 3.24 & 4.71 & 7.15 & 8.17 & 7.42 & 0.65 & 72 \\
\hline$X V$ & $\begin{array}{c}\mathrm{C}_{42} \mathrm{H}_{31} \mathrm{O}_{8} \mathrm{~N}_{4} \mathrm{~S}_{2} \\
(783)\end{array}$ & 64.37 & 63.51 & 3.96 & 3.24 & 4.71 & 7.15 & 8.17 & 7.42 & 0.43 & 64 \\
\hline XVII & $\begin{array}{c}\mathrm{C}_{45} \mathrm{H}_{37} \mathrm{O}_{8} \mathrm{~N}_{4} \mathrm{~S}_{2} \\
(825)\end{array}$ & 65.45 & 64.16 & 4.48 & 4.09 & 6.79 & 6.10 & 7.76 & 7.22 & 0.72 & 56 \\
\hline
\end{tabular}

${ }^{*} \eta$ Inherent viscosity measured in $\mathrm{H}_{2} \mathrm{SO}_{4}$ at $30^{\circ} \mathrm{C}$.

\subsection{Synthesis of Copolyamides XIII-XVII}

The same method, which applied in the synthesis of the polyamides, was also applied in the synthesis of the copolyamides.

Typically, in a 100-ml round-bottomed flask equipped with a magnetic stirrer and nitrogen inlet and outlet was placed a solution of $0.762 \mathrm{~g}(3 \mathrm{mmole})$ of diacid chloride IV, 2,6-bis(m-nitrobenzylidene) methylcyclohexanone VII and $0.780 \mathrm{~g}$ (3 mmole) of 2,6-Bis $(m-$ aminobenzylidene) ter.butyl-cyclohexanone VIII. The flask was purged with nitrogen while stirring, and $2.66 \mathrm{~g}$ (20 mmole) of aluminum chloride was added during the nitrogen flash. The reddish brown reaction mixture was stirred for $24 \mathrm{hrs}$ then it was filtered off and the separated product was triturated three times with a large excess of methanol. The powdery material was again filtered off, washed with water, methanol, and acetone and dried under reduced pressure $(1 \mathrm{mmHg})$ at $70^{\circ} \mathrm{C}$ for 2 days. This method was applied for the synthesis of other copolyamides; whose yield, elemental analysis, viscosity and colors are also listed in Table 1.

\section{RESULTS AND DISCUSSION}

\subsection{Synthesis of 2,7- Dichloroformylthianthrene-- $5,5^{\circ}, 10,10^{`}$-tetraoxide (IV)}

A thianthrene precursor was prepared as described in the literature [20] by reaction of sulfur and benzene with $\mathrm{AlCl}_{3}$ in the presence of carbon disulfide as a reaction medium to afford thianthrene in good yield. Acetylation of thianthrene with acetyl chloride by a Friedel-Crafts reaction catalyst was used to obtain II. By oxidation of II with $\mathrm{KMnO}_{4}$ in week basic medium at $\mathrm{pH} 8.5$, III was established in good yield, $\mathrm{mp}>300^{\circ} \mathrm{C}$. The corresponding acid chloride IV was acquired in $87 \%$ yield by the interaction of the diacid III with excess thionyl chloride and a few drops of pyridene as catalyst. All steps followed for the preparation of IV are depicted in Scheme 1.

\subsection{Synthesis of Diarylidene Monomers VI and VIII}

Scheme 2 formulates the methods utilized for the preparation of the diarylidenecycloalkanone monomers VI and VIII. As shown, these monomers were prepared by the base-catalyzed condensation of two moles of $m$ nitrobenzaldehyde with one mole of methylcyclohexanone or, tert.butyl cyclohexanone followed by hydrogenation using palladium on activated carbon in ethanol at $50^{\circ} \mathrm{C}$. Note that the hydrogenation step in Scheme 2 should not be excessively prolonged in order to the presence of carbonyl and olefinic function. The IR and ${ }^{1} \mathrm{H}-\mathrm{NMR}$ spectra of these two monomers did not show detectable hydrogenation of these segments under the particular experimental conditions employed. Moreover, literature survey revealed that hydrogenation of the cyclohexanone carbonyl group requires acidic medium, a platinum catalyst, and a pressure of $30-45$ psi to preferentially give the axial alcohol [22]. 

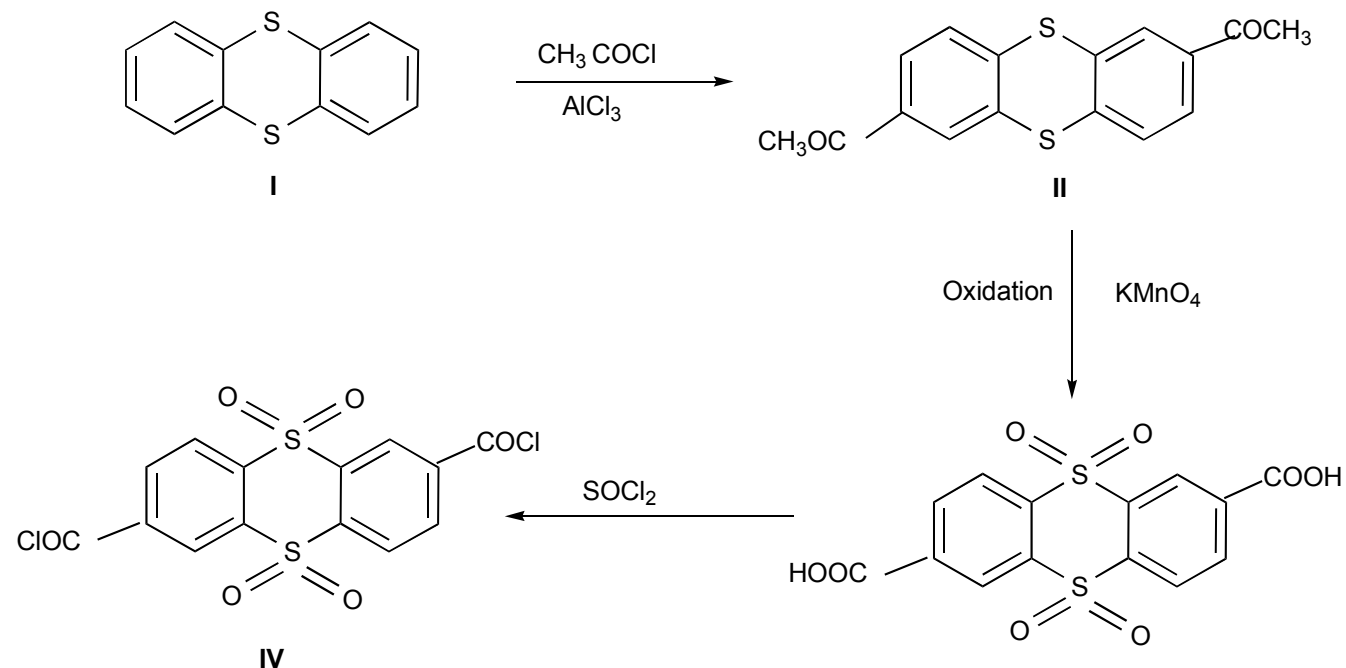

IV

Scheme 1: Synthesis of 2,7-Dichloroformylthianthrene-5,5 $, 10,10^{\circ}$ - tetraoxide IV.<smiles>CCC(O)C(C)O</smiles>

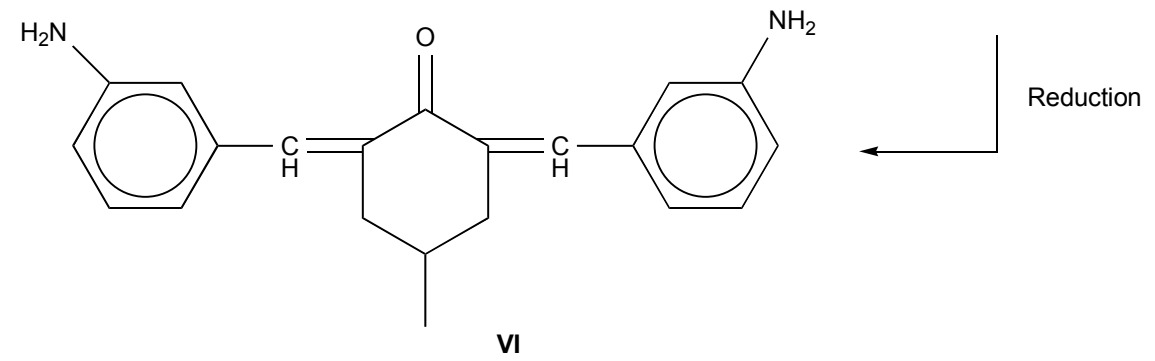<smiles>CC(C)(C)C1CC(=Cc2cccc([N+](=O)[O-])c2)C(=O)C(=Cc2cccc([N+](=O)[O-])c2)C1</smiles><smiles>[R20]CCCCCCCCC(C)(C)C</smiles>

Scheme 2: Synthesis of Diarylidene Monomers V and VIII. 


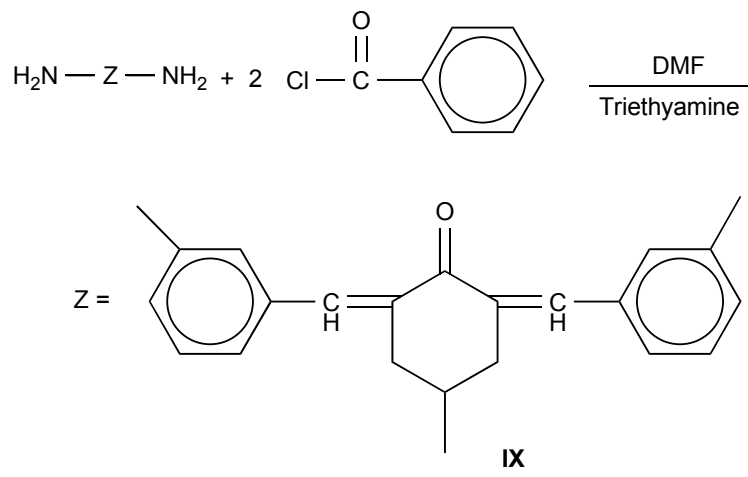

IX

Scheme 3: Synthesis of Model Compounds IX and X.

\subsection{Synthesis of Model Compounds IX and X}

Before attempting the polymerization, model compounds were prepared by the reaction of diamines (VI and VIII) with two equivalent of benzoylchloride. A typical example is the reaction of 2 mols of benzoylchloride with $1 \mathrm{~mol}$ of VI. The identity of these model compounds were confirmed by both elemental and spectral IR and ${ }^{1} \mathrm{H}$ NMR data (Scheme 3).

\subsection{Synthesis of Polyamides XI and XII}

A new class of polyamides $\mathbf{X I}$, XII containing dibenzylidenecycloalkanone in the main chain were prepared from the polymerization of $\mathbf{I X}$ and XII with diacid chloride IV as shown in Scheme 4.

\subsection{Synthesis of Copolyamides XIII-XVII}

Unreported copolyamides XIII-XVII containing two dibenzylidenecycloalkan-one different moieties e.g. bis benzylidene methylcyclohexanone, and bisbenzylidene tert.butyl cyclohexanone in the polymer main chain. These two copolyamides were synthesized from the copolymerization of the two monomers $\mathrm{VI}$ and VIII with the diacid chlorides IV as shown in Scheme $\mathbf{5}$.

Polyamides and copolyamides were synthesized by low temperature solution polycondensation technique [23] in a solvent like NMP which dissolves the diamines and acts as a good acid acceptor for the $\mathrm{HCl}$ liberated during the polymerization reaction and also in the presence of $\mathrm{LiCl}$, as catalyst. $\mathrm{LiCl}-\mathrm{NMP}$ solution is powerful enough to keep the growing polymer chain in solution as its molecular weight builds up. Reaction times varied from 5-6 hrs. Polyamides were immediately isolated (see experimental part) when the reaction solution was poured into an ice/water mixture, with yields in the range of $56-77 \%$. The polymerization proceeded rapidly to yield high molecular weight polyamides with inherent viscosities in the range 1.08$0.65 \mathrm{dL} / \mathrm{g}$. The resulting polyamides were characterized by elemental analysis, FT-IR, solubility, viscosity measurements, thermal analysis, and morphological properties.The elemental analyses of all the different

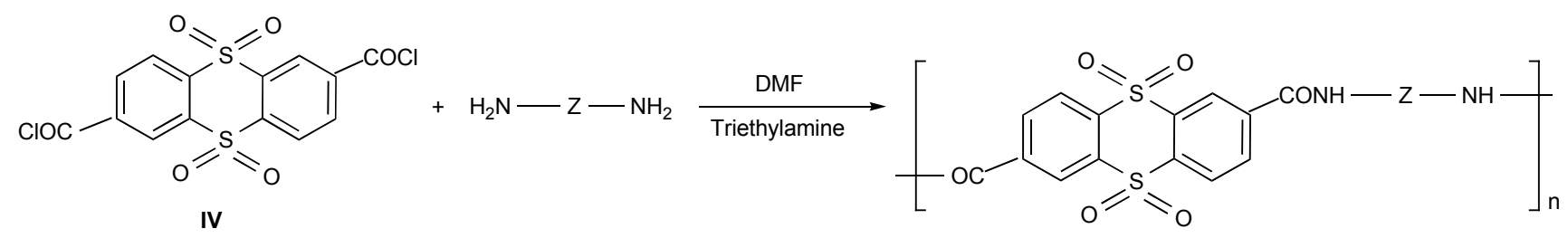

IV

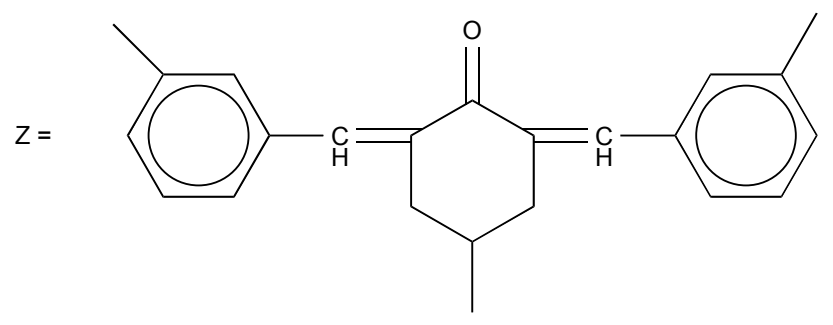

$\mathbf{X I}$

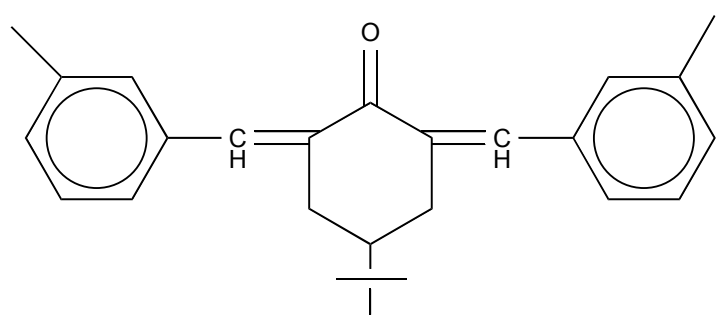

XII

Scheme 4: Synthesis of Polyamides XI and XII. 


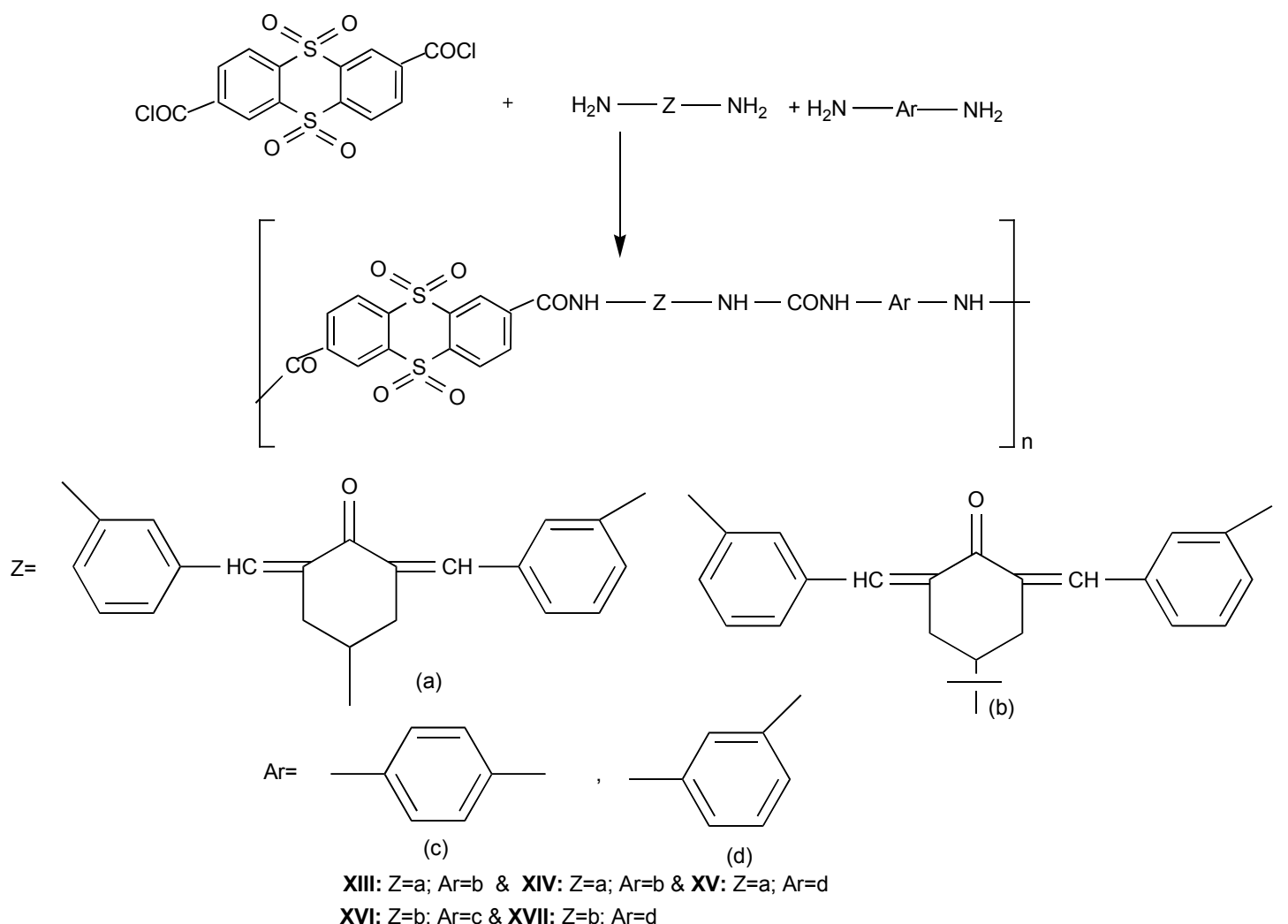

Scheme 5: Synthesis of Copolyamides XIII-XVII.

polymers coincided with the characteristic repeating units of each polymer. It should be noted that the elemental analyses for the polymers deviated up to $1.29 \%$ from the theoretical values. However, it is not uncommon for polymers to trap solvents within the matrix, especially for polyamides of high molecular mass and those containing polar groups, which are capable of hydrogen bonding with solvent molecules [24].

Spectral data supported the structural assignments for the polyamides and copolyamides are in good agreement with spectral data obtained for the model compounds. The IR data obtained in $\mathrm{KBr}$ discs for all the polyamides and its copolyamides showed the absorption band for $\mathrm{N}-\mathrm{H}$ stretching at $3350-3200 \mathrm{~cm}^{-1}$ characteristic for secondary amino group. The appearance of carbonyl absorptions at $1630-1650 \mathrm{~cm}^{-1}$, known as the amide I band, is due to carbonyl stretching vibration. A strong amide II band, due to the coupling of N-H bending and C-N stretching of the C-N$\mathrm{H}$ group was noted at $1535-1515 \mathrm{~cm}^{-1}$. In addition, $1630-1645 \mathrm{~cm}^{-1}$ for $(\mathrm{C}=\mathrm{O}$, cycloalkanone $)$, and at 1590 $1600 \mathrm{~cm}^{-1}$ for $(C=C)$ were found. The lowering of the usual carbonyl frequency from 1715 to $1690-1680 \mathrm{~cm}^{-1}$ is due to the resonance effect [25]. Because the polyamides were examined in the solid state, hydrogen bonding could be the major contributing factor in their lower carbonyl absorption frequency [26].

\subsection{Polymer Characterization}

The various characteristics of the resulting polyamides including: solubility, viscometry, X-ray diffraction analysis, thermal analysis, and morphological properties were also determined and the data were discussed below.

The solubilities of the polyamides $\mathbf{X I}$, XII and copolyamides XIII-XVII were tested in various solvents including: DMSO, DMF-DMA mixture (1:1 ratio), NMP, $\mathrm{CHCl}_{3}$,-acetone mixture (1:1 ratio), THF, Methylene chloride, and concentrated $\mathrm{H}_{2} \mathrm{SO}_{4}$. It was found that polyamide XI partially soluble in DMSO, DMF-DMA mixture (1:1 ratio), NMP, $\mathrm{CHCl}_{3}$,-acetone mixture (1:1 ratio), THF, Methylene chloride, while polyamide $\mathrm{XII}$, is completely soluble in those solvents due to the presence of tert.alkyl group as pendant group. All the copolyamides were completely soluble in DMSO. In strong protic solvent such as concentrated $\mathrm{H}_{2} \mathrm{SO}_{4}$, all the polyamides and copolyamides were completely soluble, giving a violet color (see Table 2).

The inherent viscosities $\left(\eta_{\text {inh }}\right)$ of polyamides $\mathbf{X I}$, XII and copolyamides XIII-XVII were determined in 
Table 2: Solubility Characteristics of Polyamides XI, XII and Copolyamides XIII-XVII

\begin{tabular}{|c|c|c|c|c|c|c|}
\hline $\begin{array}{c}\text { Polymer } \\
\text { code }\end{array}$ & DMSO & $\begin{array}{c}\text { DMF-DMA } \\
(1: 1)\end{array}$ & NMP & $\begin{array}{c}\text { Chloroform } \\
\text { Acetone } \\
(1: 1)\end{array}$ & $\begin{array}{c}\text { THF } \\
\text { chloride }\end{array}$ \\
\hline \hline XI & \pm & \pm & \pm & \pm & \pm & + \\
\hline XII & + & + & + & + & + & + \\
\hline XIII & + & \pm & \pm & + & \pm & + \\
\hline XIV & + & + & \pm & \pm & \pm & + \\
\hline XV & + & \pm & \pm & \pm & \pm & + \\
\hline XVI & + & \pm & \pm & + & \pm & + \\
\hline XVII & + & + & \pm & + & + \\
\hline
\end{tabular}

(+) Soluble at room temperature RT.

$( \pm)$ Partially soluble at RT

(-) Insoluble.

concentrated sulphuric acid $\left(\mathrm{H}_{2} \mathrm{SO}_{4}\right)$ at $30^{\circ} \mathrm{C}$ with an Ubbelohde suspended level viscometer. The inherent viscosity value is defined as:

$$
\eta_{\text {inh }}=\left[2.3 \log \eta / \eta_{0}\right] / C
$$

The solution concentration $C$ is $0.5 \mathrm{~g} / 100 \mathrm{ml}, \eta / \eta_{o}=$ relative viscosity (or viscosity ratio). It can be shown from Table 1 that copolyamide XVI had low viscosity $(0.35 \mathrm{dL} / \mathrm{g})$ and this may be attributed to low molecular weight of the polymer. On the other hand, the inherent viscosity of the polyamides XII \& XI is higher ( 0.89 and $0.73 \mathrm{dL} / \mathrm{g}$ respectively) which may be attributed to high molecular weight of these polymers.

The X- ray diffractograms of selected examples of polyamides XI and copolyamide XVII (Figures 1, 2) were measured in the region $2 \theta=5-60^{\circ}$. The selected examples were crystalline or semicrystalline, this may be due to the presence of cyclohexyl moiety in the backbone as well as the presence of different structure, which may be due to the increase in the polymer chain flexibility and that might be responsible for the approach and mutual attractions of adjacent chains [27]. While the degree of crystallinity varied from polymer to another depending on the rest of structures. The higher degree of crystallinity in the two series may be attributed to a large class of structures that are intermediate in the ordered states between crystals in the arrangement of their atoms and molecules. Moreover, the presence of $\mathbf{C}=\mathbf{O}$ polar group, in addition to high $\mathbf{C}=\mathbf{C}$ band levels induces some order between two adjacent "chains of the polymers, leading to some extended crystallinity".

The morphology of polyamides was examined by scanning electron microscopy (SEM) using a Jeol JSM5400 LV instrument as described in our previous work [28]. The SEM study of the selected example of

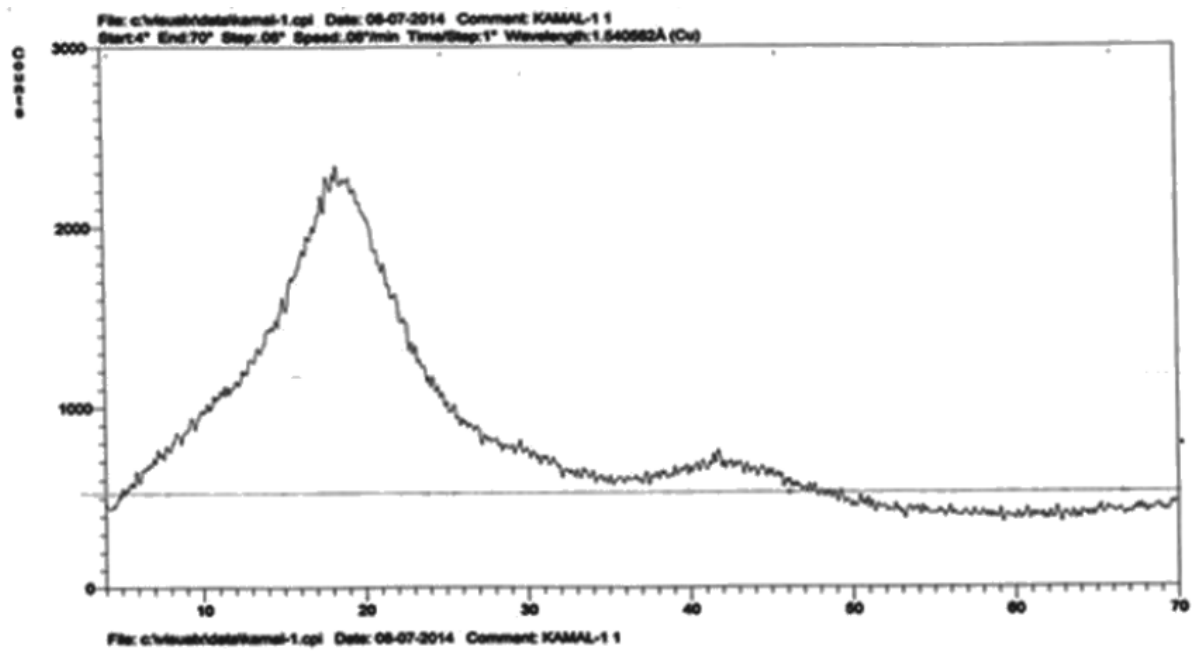

Figure 1: X-ray Diffraction pattern of polyamide XI. 


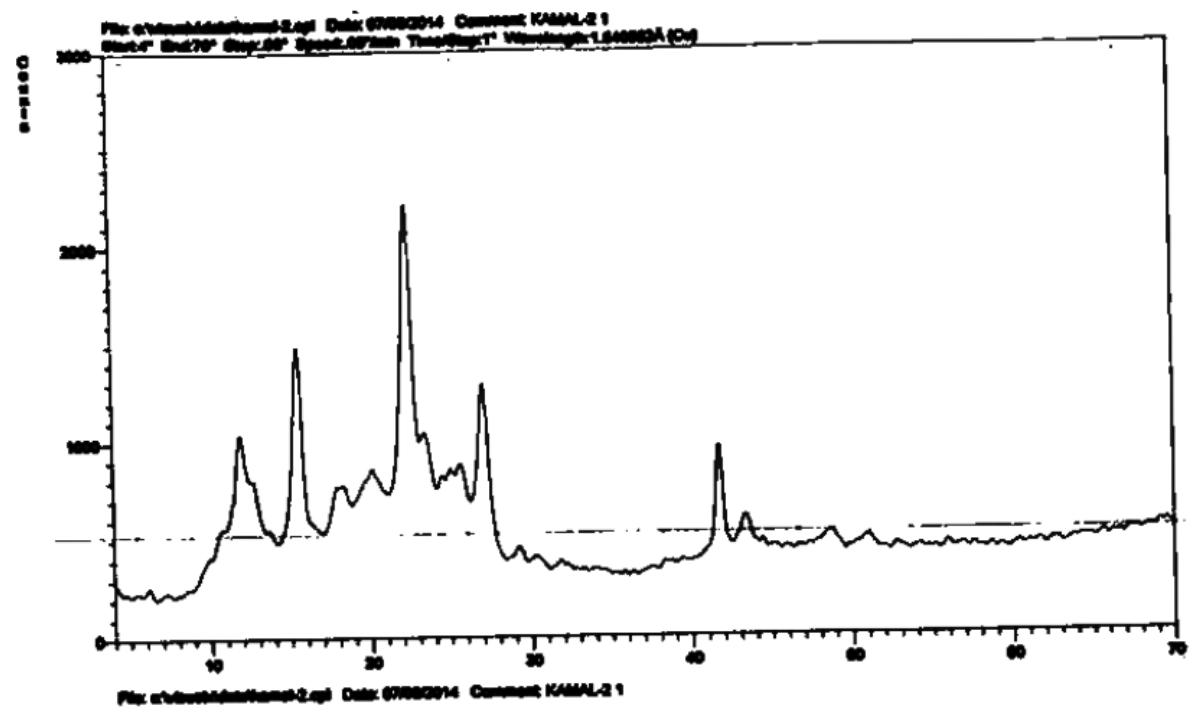

Figure 2: X-ray Diffraction pattern of copolyamide XVII.

polyamide XI Figure 3a was examined using SEM measurement to show the surface of the polymer and to study the effect of substituent on the surface of the polymer molecules by comparison the images in each case. The study of selected example of polyamides showed that the surface of polyamide XI Figure $3 \mathbf{a}$, magnification $X=500$, consisted of globular grains with coalescence, with higher magnification $X=1000$ (Figure 3b) showed accumulative particles with globular and semi-globular grains.

The thermal behavior of polyamides $\mathbf{X I}, \mathbf{X I I}$ and copolyamides XIII-XVII, was evaluated by thermogravimetric analysis (TGA) and differential thermal analysis (DTA) in nitrogen at a heating rate of $10^{\circ} \mathrm{C} / \mathrm{min}$. The $\mathrm{TG}$ curves of these polyamides are given in Figures $\mathbf{4}, \mathbf{5}$ while Table $\mathbf{3}$ gives the temperatures for various percentage weight losses. All the polyamides showed similar decomposition patterns. The temperature for a $10 \%$ weight loss is considered to be the polymer decomposition point, and it ranged between 375 and $410^{\circ} \mathrm{C}$. The initial decomposition of these polymers $(10 \%$ loss $)$ is considered to be the polymer decomposition temperature (PDT) $[28,29]$ it occurred in the range $215^{\circ} \mathrm{C}$ to $239^{\circ} \mathrm{C}$ for the synthesized polyamides. The effect of alkyl pendant group on the thermal stability of polyamides can be seen from Table 3 , polyamide XII which contain the tert. butyl group, is less thermally stable than other polymers which contain the methyl group. Introduction

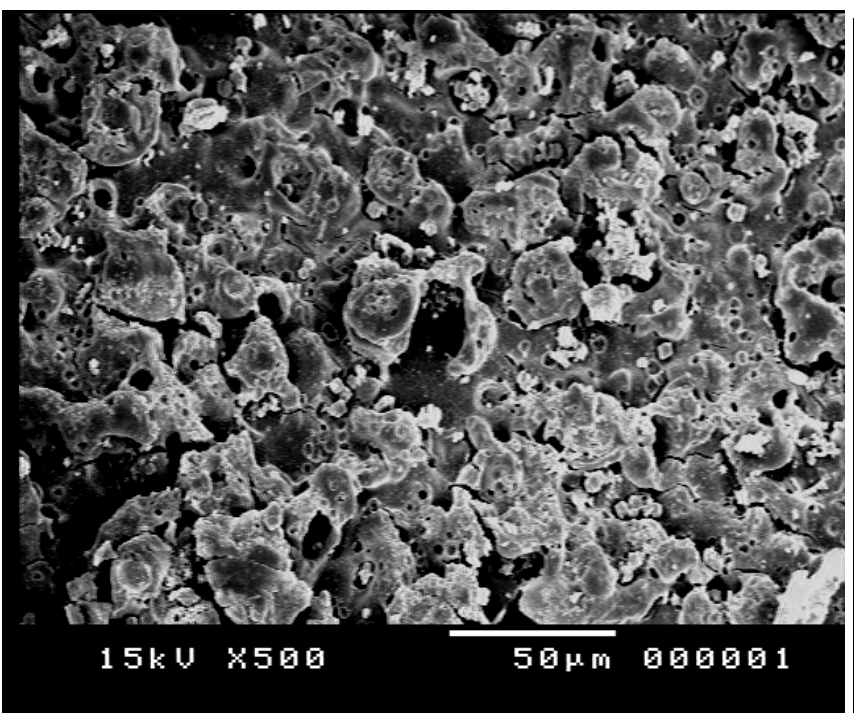

(a)

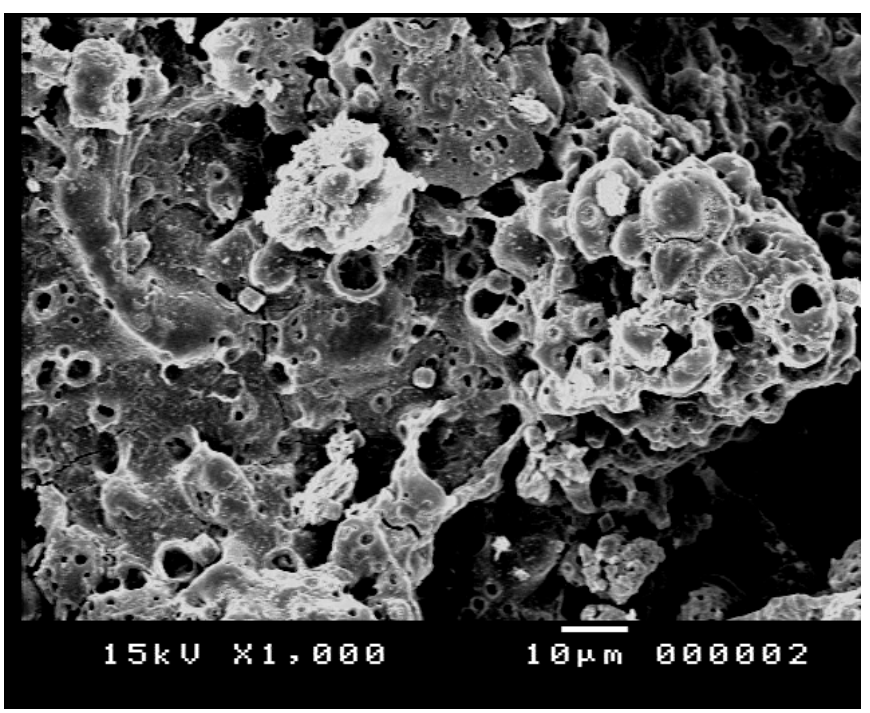

(b)

Figure 3: SEM images of polyamide $\mathbf{X I}$ surface at different magnifications, $a: x=500$; and $b: x=1000$. 


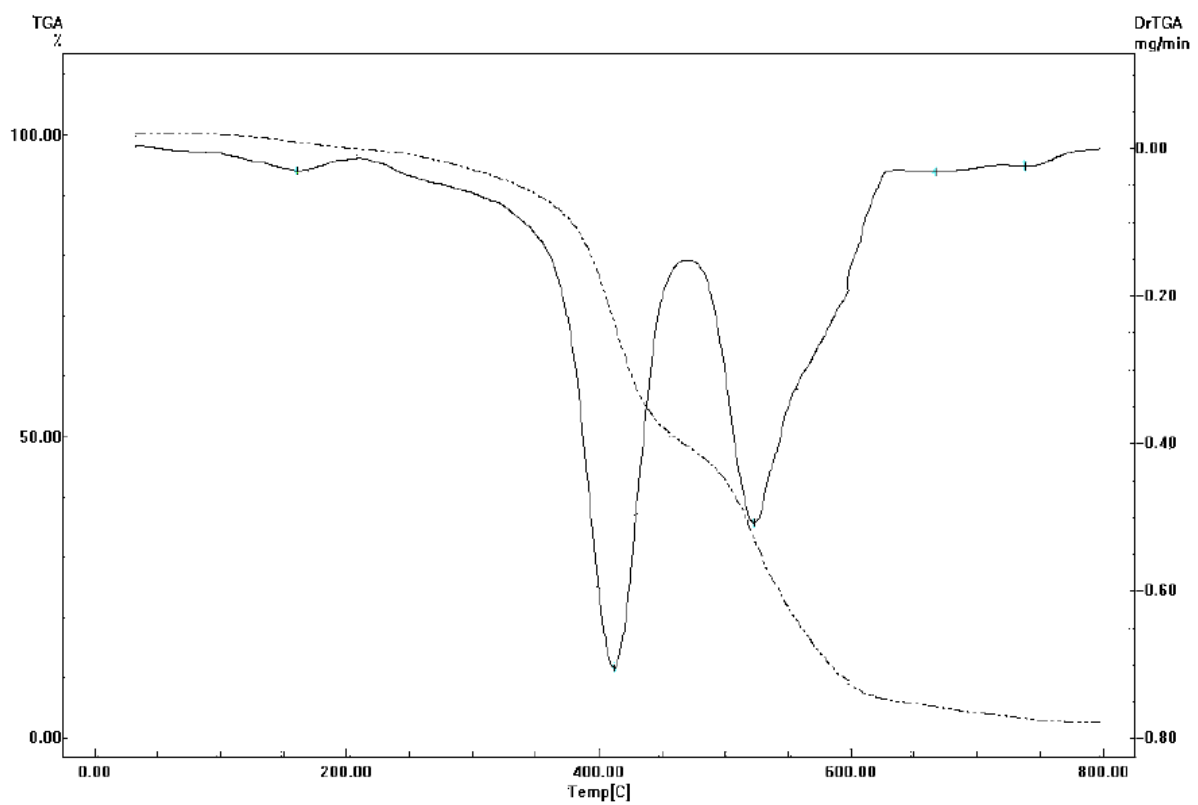

Figure 4: The TGA and Dr TGA traces of polyamide $\mathbf{X I}$ in nitrogen at a heating rate of $10^{\circ} \mathrm{C} / \mathrm{min}$.

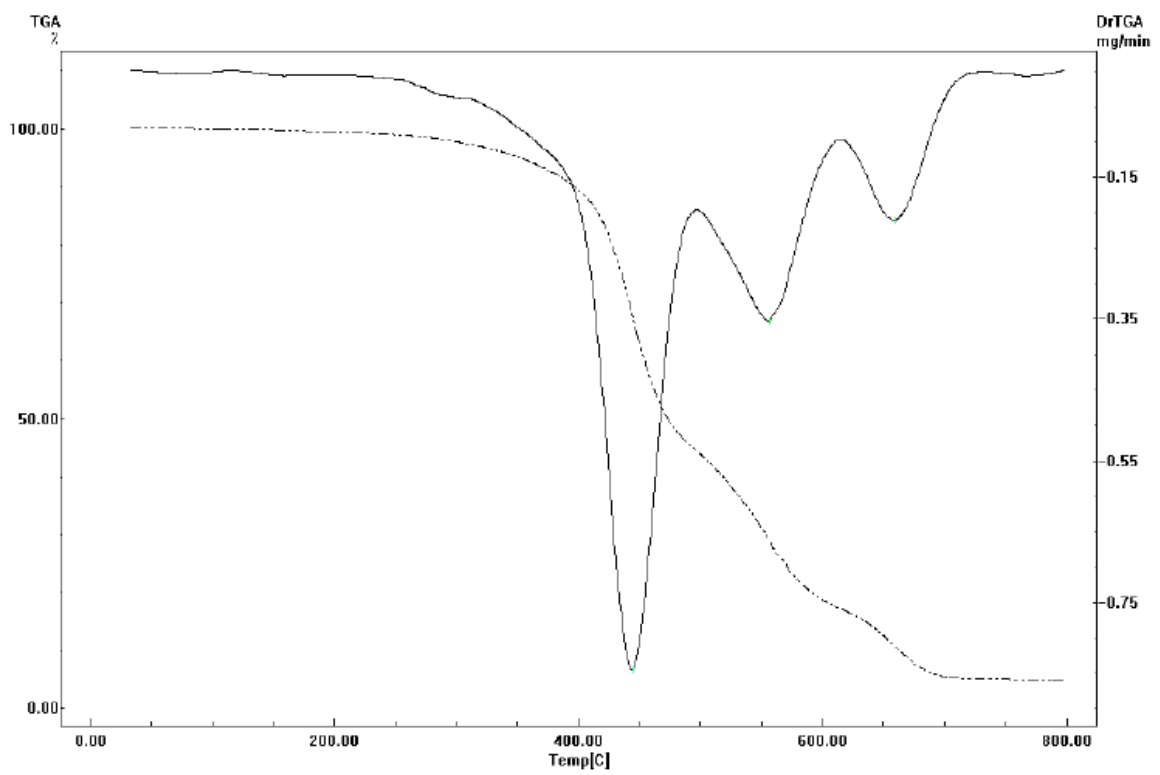

Figure 5: The TGA and Dr TGA traces of copolyamide XVI in nitrogen at a heating rate of $10^{\circ} \mathrm{C} / \mathrm{min}$.

of the cyclohexanone ring in a polymer decreases stability: polyamide $\mathbf{X I}$ loses $10 \%$ at $410^{\circ} \mathrm{C}$ and polyamide XII loses $10 \%$ at $400^{\circ} \mathrm{C}$. This decrease of stability may be attributed to the presence of branched tert.butyl group attached with the cyclohexyl ring. The prepared polyamide $\mathbf{X I}$ was cast into a self-supporting film from a dichloromethane solution $(5 \% \mathrm{w} / \mathrm{v})$. The cast film was compact and transparent, with a faint yellow color. The electrical conductivity of the prepared polyamides XI and XII was measured by the Arrhenius technique and gave values in the range $10^{-11}-10^{-12}$ $\mathrm{Ohm} \mathrm{cm}^{-1}$. This indicates that all the polyamides are insulators.

\section{CONCLUSIONS}

Linear unsaturated polyamides and copolyamides based on diarylidenecyclohexanone and containing thianthrene moiety in the main chain have been synthesized. A solution polymerization technique at low temperature was used. All the polyamides were soluble in DMSO and strong acid solvents. Thermogravimetric analyses showed that the polyamide based on cyclopentanone was somewhat more thermally stable than cyclohexanone based polyamide. Polymers containing diarylidene-tert. butyl-cyclohexanone had more slightly higher degree of crystalinity than those 
Table 3: Thermal Properties of Polyamides XI, XII and Copolyamides XIII-XVII

\begin{tabular}{|c|c|c|c|c|c|}
\hline \multirow{2}{*}{$\begin{array}{c}\text { Polymer } \\
\text { Code }\end{array}$} & \multicolumn{5}{|c|}{ Temperature $\left({ }^{\circ} \mathrm{C}\right)$ for various decomposition levels } \\
\hline & $10 \%$ & $20 \%$ & $30 \%$ & $40 \%$ & $50 \%$ \\
\hline $\mathbf{X I}$ & 410 & 450 & 455 & 485 & 510 \\
\hline XII & 400 & 425 & 460 & 470 & 480 \\
\hline XIII & 395 & 410 & 430 & 450 & 485 \\
\hline XIV & 390 & 405 & 450 & 470 & 490 \\
\hline $\mathbf{X V}$ & 385 & 425 & 460 & 470 & 480 \\
\hline $\mathbf{X V I}$ & 390 & 410 & 430 & 450 & 485 \\
\hline XVII & 375 & 405 & 450 & 470 & 490 \\
\hline
\end{tabular}

*Heating rate: $10^{\circ} \mathrm{C} \mathrm{min}^{-1}$.

containing diarylidene-methyl-cyclohexanone. The electrical conductivity of the prepared polyamides was measured by the Arrhenius technique and gave values in the range $10^{-11}-10^{-12} \mathrm{Ohm} \mathrm{cm}^{-1}$. This indicated that all the polyamides were used as insulators.

\section{REFERENCES}

[1] Cassidy PE. Thermally Stable Polymers, Marcel Dekker: New York 1980.

[2] Yang $\mathrm{HH}$. Aromatic High Strength Fibres, Wiley and Sons: New York 1989.

[3] Jadhav JY, Preston J, Krigbaum WR. J Polym Sci Part A: Polym Chem 1989; 2: 1175. http://dx.doi.org/10.1002/pola.1989.080270407

[4] Ringsdorf $\mathrm{H}$, Tschirner $\mathrm{P}$, Schonherr $\mathrm{OH}$, Wendorff $\mathrm{JH}$. Makromol Chem 1987; 188: 1431. http://dx.doi.org/10.1002/macp.1987.021880619

[5] Oishi Y, Takado H, Yoneyama M, Kakimoto MA, Imai Y. J Polym Sci Part A: Polym Chem 1990; 28: 1763. http://dx.doi.org/10.1002/pola.1990.080280708

[6] Preston J. J Polym Sci Part A: Polym Chem 1966; 4: 529. http://dx.doi.org/10.1002/pol.1966.150040307

[7] Bair TI, Morgan PW, Killian FL. Macromolecules 1977; 10: 1396. http://dx.doi.org/10.1021/ma60060a042

[8] Hsiao SH, Yang CP. J Polym Sci Part A: Polym Chem 1990; 28: 2169. http://dx.doi.org/10.1002/pola.1990.080280812

[9] Gaudiana RA, Minns RA, Rogers HG, Sinta R, Taylor LD, Kalyanaraman P, McGowan C. J Polym Sci Part A: Polym Chem 1987; 25: 1249. http://dx.doi.org/10.1002/pola.1987.080250505

[10] Idage SB, Idage BB, Shinde BM, Vernekar SP. J Polym Sci Part A: Polym Chem 1989; 27: 583. http://dx.doi.org/10.1002/pola.1989.080270218

[11] Hsiao SH, Yang CP. J Polym Sci Part A: Polym Chem 1990; 28: 2501. http://dx.doi.org/10.1002/pola.1990.080280922

[12] Preston M. J Polym Eng Sci 1975; 15: 199. http://dx.doi.org/10.1002/pen.760150312
[13] Griffin AC, Britt TR, Campbell GA. Mol Cryst Liq Cryst 1982; 82: 145.

http://dx.doi.org/10.1080/01406568208070174

[14] Cowrie JMG, Wu HH. Br Polym J 1988; 20: 515. http://dx.doi.org/10.1002/pi.4980200609

[15] Balaff M, Schmidt GF. Makromol Chem Rapid Commun 1987; 8: 93.

http://dx.doi.org/10.1002/marc.1987.030080206

[16] Kricheldorf HR, Schmidt B, Delius U. Eur Polym J 1990; 26 : 791.

http://dx.doi.org/10.1016/0014-3057(90)90131-M

[17] Aducci J, Chapoy LL, Jonsson G, Kops J, Shinde BM. Polym Eng Sci 1983; 28: 2069.

[18] Aducci J, Chapoy LL, Jonsson G, Kops J, Shinde BM. Polym Eng Sci 1981; 21: 712. http://dx.doi.org/10.1002/pen.760211114

[19] Perrin DD, Armergo WLF, Perrin DR. Purification of Laboratory Chemicals, $2^{\text {nd }}$ ed., Pergamon, New York 1980.

[20] Dougherty G, Hammond PD. J Am Chem Soc 1935; 57: $117-$ 118.

http://dx.doi.org/10.1021/ja01304a031

[21] Srinivasan RM, Bassler GC, Morrill TC. Spectrometric Identification of Organic Compounds, Wiley, New York 1974.

[22] Augustine RL. Catalytic Hydrogenation; Dekker: New York, 19 XX; pp. 58-87.

[23] Aly KI and Kandeel MM. High Perform Polym 1996; 8: 307314.

[24] Bair TI, Morgan PW, Killian FL. Macromolecules 1977; 10(6): 1396-1400.

[25] Starr L. J Polym Sci Polym Chem Ed 1966; 12: 3041-3046. http://dx.doi.org/10.1002/pol.1966.150041210

[26] Skoog DA, West DM. Principles of Instrumental Analysis Holts Rinehart \& Winston, New York 1971.

[27] Eliel EL, Allinger NL, Angyal SJ, Morrison GA. Conformational Analysis, Wiley, New York 1981.

[28] Aly KI. Polymer International 1998; 47(4): 483-490. http://dx.doi.org/10.1002/(SICl)10970126(199812)47:4<483::AID-PI91>3.0.CO;2-F

[29] Abd-Alla MA, Aly KI, Hammam AS. High Performance Polymers 1989; 1: 323-334. 